\title{
CONSIDERATION OF POUNDING AND SSI IN ENERGY-BASED SEISMIC DESIGN OF BUILDINGS
}

\author{
A. Kharazian ${ }^{1}$, F. López-Almansa ${ }^{2}$, A. Benavent-Climent ${ }^{3}$ \\ ${ }^{1}$ Civil and Environmental Engineering Department, Technical University of Catalonia, Campus Nord \\ UPC, 08034 Barcelona, alireza.kharazian@upc.edu \\ ${ }^{2}$ Architecture Technology Department, Technical University of Catalonia, Avda. Diagonal 649, 08028 \\ Barcelona, francesc.lopez-almansa@upc.edu. Currently Associate Researcher RiNA, Institute of Civil \\ Works, Austral University of Chile, Valdivia \\ ${ }^{3}$ Mechanical Engineering Department, Technical University of Madrid, C. José Gutiérrez Abascal 2, \\ 28006 Madrid, amadeo.benavent@upm.es
}

\begin{abstract}
The energy demand on a given construction is commonly determined, in terms of equivalent velocity, from smoothed design spectra that are ordinarily derived after dynamic analyses on SDOF systems. The application to actual multi-story buildings is far from trivial, given that their behavior must be characterized with MDOF models; in this context, a relevant issue is the distribution of energy along the building height. In other words, additional research is required to further promote the development of the energy-based approach. Thus, this work addresses two issues not sufficiently covered in past studies: the influence of soil-structure interaction (SSI), and pounding between adjoining buildings. The study begins by selecting four low-rise (3 and 5-story) RC frame buildings and four representative severe ground motion records (i.e. historic accelerograms). Such inputs are selected with respect to their most relevant characteristics: frequency content (indirectly represented by the soil type) and relevance of velocity pulses (forward-directivity effects). Then, 2-D nonlinear dynamic analyses are performed on single (lone) buildings and on pairs of colliding buildings. These calculations provide the total input and hysteretic energy and their distribution among the building stories. Such results are compared with those from a more simplified approach (i.e. the individual energy spectra of the considered inputs), and relevant conclusions are derived. Preliminary results show that the comparison between the energies determined with the two abovementioned approaches shows a reasonable fit, and that the influence of SSI proves significant. Regarding pounding, it does not alter significantly the total input and hysteretic energy, but their distribution among the floors changes considerably, concentrating in the colliding floors.
\end{abstract}

Keywords: Energy-based design, hysteretic energy, seismic pounding, soil-structure interaction 


\section{INTRODUCTION}

The seismic demand, on a given construction, in form of input and hysteretic energy, is commonly determined after smoothed design spectra; in these spectra, energy is expressed in terms of equivalent velocity. Such spectra are ordinarily derived after dynamic analyses on nonlinear SDOF systems. The application of this approach to actual multi-story buildings is far from trivial, given that their behavior cannot be characterized with SDOF but requiring MDOF models (at least one DOF per floor in symmetric buildings or three in asymmetric buildings); for example, in this context, a relevant issue is the distribution of energy along the building height. In other words, additional research is required to further promote the development of the energy-based design approach.

In the context of seismic energy-based design of buildings, this work addresses two issues that have not been sufficiently covered in past studies: the influence of soil-structure interaction (SSI), and pounding between adjoining buildings. The study begins by selecting four low-rise (3 and 5-story) RC frame buildings, and four representative severe ground motion records (i.e. historic accelerograms). The buildings are designed for high seismicity regions as intermediate moment frames; regarding the inputs, are selected with respect to their most relevant characteristics: frequency content (indirectly represented by the soil type) and relevance of velocity pulses (forward directivity effects). Then, 2-D nonlinear dynamic analyses are performed on two cases: single (lone) buildings and pairs of colliding buildings. These calculations provide the total input and hysteretic energies and their distribution among the building stories. Such results are compared with those from a more simplified approach (i.e. the individual energy spectra of the considered inputs), and relevant conclusions are derived. Preliminary results show that the comparison between the energies determined with the two abovementioned approaches (i.e. using the smoothed spectra of a SDOF system and directly with nonlinear time-history analysis of MDOF systems) shows a reasonable fit, and that the influence of SSI proves significant. Regarding pounding, preliminary results show that it does not alter significantly the total input and hysteretic energy, but their distribution among the floors changes (although not as considerably as might be expected), concentrating in the colliding floors.

This work is a part of a wider research effort oriented to investigate the seismic pounding between pairs of buildings with aligned slabs. This research involves deep discussion on existing pounding models [Kharazian, Lopez-Almansa 2017], proposing new criteria for estimating the damping parameter of the Kelvin-Voigt model [Kharazian 2017; López Almansa, Kharazian 2018], performing a parametric study on the effects of pounding between short-to-mid height RC buildings [Kharazian 2017], and conducting experiments aimed to clarify the most controversial and less studied issues [Kharazian et al. 2018].

\section{SEISMIC DESIGN BASED ON INPUT ENERGY SPECTRA}

This section briefs the basic principles of the hysteretic energy spectra, which are commonly considered for energy-based seismic design.

The nonlinear equation of motion of a SDOF system subjected to a horizontal ground motion is given by:

$$
m \ddot{x}+c \dot{x}+Q(x)=-m \ddot{x}_{\mathrm{g}}
$$

In equation (1), $x$ is the relative displacement, $m$ is the mass, $c$ is the viscous damping coefficient, $Q(x)$ is the restoring force, and $\ddot{x}_{\mathrm{g}}$ is the driving ground acceleration. Multiplying (1) by $d x=\dot{x} d t$ and integrating along the input duration, the following energy balance relation is obtained:

$$
E_{\mathrm{k}}+E_{\zeta}+E_{\mathrm{a}}=E_{\mathrm{I}}
$$


In equation (2), $E_{\mathrm{k}}$ is the relative kinetic energy, $E_{\zeta}$ is the energy dissipated by the inherent damping, $E_{\mathrm{a}}$ is the energy absorbed by the spring, and $E_{\mathrm{I}}$ is the relative input energy:

$$
\begin{aligned}
& E_{\mathrm{k}}=\int_{0}^{t} m \ddot{x} \dot{x} d t \quad E_{\zeta}=\int_{0}^{t} c \dot{x}^{2} d t \quad E_{\mathrm{a}}=\int_{0}^{t} Q(x) \dot{x} d t \quad E_{\mathrm{I}}=-\int_{0}^{t} m \ddot{x}_{\mathrm{g}} \dot{x} d t \\
& =\frac{1}{2} m \dot{x}^{2}
\end{aligned}
$$

$E_{\mathrm{a}}$ comprises both the recoverable elastic strain energy $E_{\mathrm{s}}$ and the irrecoverable hysteretic energy $E_{\mathrm{H}}$ that generates the structural damage: $E_{\mathrm{a}}=E_{\mathrm{s}}+E_{\mathrm{H}}$. In its turn, the sum of $E_{\mathrm{k}}$ and $E_{\mathrm{s}}$ constitutes the elastic vibration energy, $\left(E_{\mathrm{e}}=E_{\mathrm{k}}+E_{\mathrm{s}}\right)$, so that equation (2) can be rewritten as:

$$
E_{\mathrm{e}}+E_{\zeta}+E_{\mathrm{H}}=E_{\mathrm{I}}
$$

The difference between $E_{\mathrm{I}}$ and $E_{\zeta}$, is denominated [Housner 1956] as the energy that contributes to damage $E_{\mathrm{D}}$ :

$$
E_{\mathrm{D}}=E_{\mathrm{I}}-E_{\zeta}=E_{\mathrm{e}}+E_{\mathrm{H}}
$$

At the ground motion end, $E_{\mathrm{e}}$ is almost zero; consequently, equations (4) and (5) show that $E_{\mathrm{H}}$ can be taken as equal to $E_{\mathrm{D}}$, i.e. $E_{\mathrm{H}} \approx E_{\mathrm{D}}$. Further, $E_{\mathrm{I}}$ and $E_{\mathrm{D}}$ can be normalized by the mass $m$ and expressed in terms of equivalent velocities $V_{\mathrm{E}}$ and $V_{\mathrm{D}}$ :

$$
V_{\mathrm{E}}=\sqrt{\frac{2 E_{\mathrm{I}}}{m}} \quad V_{\mathrm{D}}=\sqrt{\frac{2 E_{\mathrm{D}}}{m}} \approx \sqrt{\frac{2 E_{\mathrm{H}}}{m}}
$$

For a given ground motion, the relationship between $V_{\mathrm{E}}$ and the natural period of the system is defined as the energy input spectrum [Akiyama 1985] (Figure 5). Noticeably, the elastic energy input spectra (i.e. obtained by assuming that the structure behaves linearly), are also valid for inelastic systems. This is because the total energy input is scarcely affected by the strength and plastification level of the system, as pointed out in the Introduction.

$V_{\mathrm{D}}$ can be determined by multiplying $V_{\mathrm{E}}$ by the $V_{\mathrm{D}} / V_{\mathrm{E}}$ ratio. Past studies [Akiyama 1985; Kuwamura, Galambos 1989; Kuwamura et al. 1994; Fajfar, Vidic 1994; Manfredi 1995; Lawson, Krawinkler 1995; Teran-Gilmore 1996; Decanini, Mollaioli 2001; Benavent et al. 2002 and 2010] showed that $V_{\mathrm{D}} / V_{\mathrm{E}}$ depends mainly on damping and ductility, and put forth empirical expressions of the ratio $V_{\mathrm{D}} / V_{\mathrm{E}}$ in terms of damping and ductility parameters. Later [Yazgan 2012; López-Almansa et al. 2013] considered as well the influence of the period of the SDOF system, and thus provided expressions depending also of such parameter.

\section{REPRESENTATIVE PROTOTYPE BUILDINGS}

The main characteristics of the selected prototype buildings are depicted in this section; a more detailed description is available in [Kharazian 2017]. Such buildings are selected to represent the most common situations in developing countries, where pounding is more feasible to occur. The buildings are assumed to be correctly designed for high seismicity regions; conversely, their gap is insufficient. This situation is frequent in developing countries, since the design commonly fulfills all the legal requirements (to obtain the construction permits) but the construction control is not completely strict. The considered buildings have plan symmetric and uniformity along their height. The reason is that most of the actual buildings fulfill such regularity conditions; moreover, irregular situations are difficult to categorize. This regularity implies that the columns are uniformly distributed and are not interrupted (i.e. continuous down to foundation), and that the story height is the same in all the floors. The cooperation of the masonry infill walls is not taken into consideration because of its lack of reliability, and because frequently the walls are separated from the main frame to allow for relative motion. Since in 
developing countries most buildings have moderate height, only short to mid-height edifices are considered. Regarding the buildings use, housing and administrative is contemplated.

After the above considerations, four prototype buildings have been selected. The buildings have RC structure with square columns, two-way solid slabs and rectangular cast-in-situ beams joining the columns, see Figure 1.

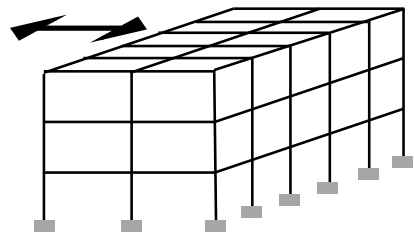

(a) Three-story two-bay building

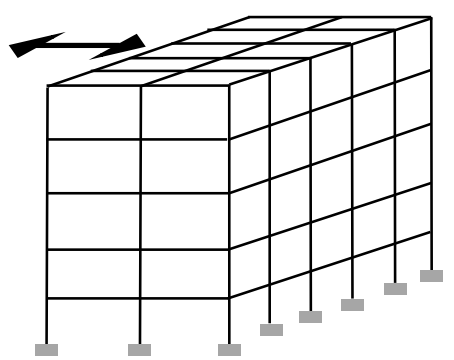

(b) Five-story two-bay building

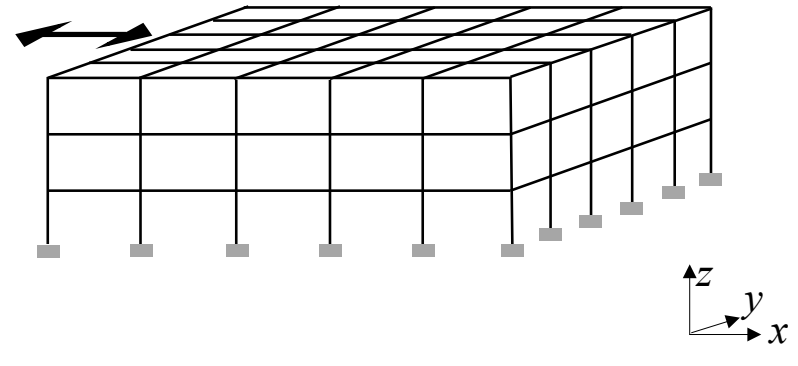

(c) Three-story five-bay building

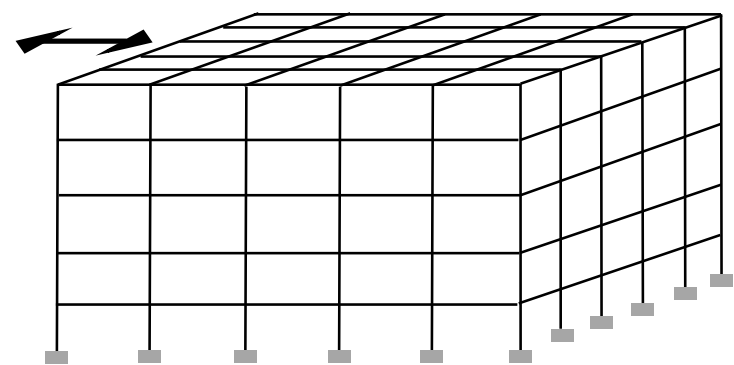

(d) Five-story five-bay building

Figure 1: Prototype buildings

As shown in Figure 1, the buildings have uniformity in elevation and symmetry in plan, with rectangular plan layout. There are no basements. There are six frames (i.e. five bays) in the direction parallel to the joint between the buildings $(y)$; in the other direction $(x)$ the number of bays of each building ranges in between two and five, to account for the differences in mass between both colliding buildings. The story height is $3.2 \mathrm{~m}$, and the span length is $5 \mathrm{~m}$ in both directions. The beams section is $40 \mathrm{~cm} \times 50 \mathrm{~cm}$, and the slabs are $15 \mathrm{~cm}$ deep. Inside each story, all the columns are alike, even their reinforcement. Table 1 depicts the column cross section, and the building height and seismic weight (corresponding to $D+0.2 L$ ).

\begin{tabular}{|c|c|c|c|c|c|c|c|}
\hline Building & $\begin{array}{c}\text { Height } \\
\text { (m) }\end{array}$ & $\begin{array}{l}1^{\text {st }} \text { floor } \\
\text { columns } \\
(\mathrm{cm})\end{array}$ & $\begin{array}{l}2^{\text {nd }} \text { floor } \\
\text { columns } \\
(\mathrm{cm})\end{array}$ & $\begin{array}{c}3^{\text {rd }} \text { floor } \\
\text { columns } \\
(\mathrm{cm})\end{array}$ & $\begin{array}{c}{4^{\text {th }}}_{\text {floor }} \\
\text { columns } \\
(\mathrm{cm})\end{array}$ & $\begin{array}{c}5^{\text {th }} \text { floor } \\
\text { columns } \\
(\mathrm{cm})\end{array}$ & $\begin{array}{c}\text { Weight } \\
(\mathbf{k N})\end{array}$ \\
\hline $\begin{array}{l}\text { 3-story } \\
\text { 5-bay }\end{array}$ & 9.6 & $60 \times 60$ & $\begin{array}{c}\text { 55-story 5- } \\
\text { bay5 }\end{array}$ & $50 \times 50$ & - & - & 3709 \\
\hline $\begin{array}{l}\text { 3-story } \\
\text { 2-bay }\end{array}$ & 9.6 & $60 \times 60$ & $\begin{array}{c}\text { 55-story 5- } \\
\text { bay5 }\end{array}$ & $50 \times 50$ & - & - & 1526 \\
\hline $\begin{array}{l}\text { 5-story } \\
5 \text {-bay }\end{array}$ & 16 & $60 \times 60$ & $\begin{array}{c}\text { 55-story } 5 \text { - } \\
\text { bay5 }\end{array}$ & $50 \times 50$ & $45 \times 45$ & $40 \times 40$ & 6067 \\
\hline $\begin{array}{l}\text { 5-story } \\
\text { 2-bay }\end{array}$ & 16 & $60 \times 60$ & $\begin{array}{c}\text { 55-story 5- } \\
\text { bay5 }\end{array}$ & $50 \times 50$ & $45 \times 45$ & $40 \times 40$ & 2486 \\
\hline
\end{tabular}


The seismic design of the buildings is performed for $0.4 \mathrm{~g}$ zero period spectral acceleration (PGA), corresponding to 475 years return period (10\% probability of being exceeded in 50 years). The seismic design category is $\mathrm{D}$, the structure in an intermediate $\mathrm{RC}$ frame, and $R=5$ has been assumed. The foundation consists either in isolated (pad or spread) footings (connected with ties) or a mat (slab).

\section{NUMERICAL MODELING}

\subsection{Numerical model of pounding}

The pounding effect is described with concentrated linear Kelvin-Voigt models (parallel combination of a spring and a dashpot) [Anagnostopoulos 1988; Kharazian, Lopez-Almansa 2017; López-Almansa, Kharazian 2018]. Figure 2.a displays such a model; $m_{1}$ and $m_{2}$ represent the lumped colliding masses, $x_{1}$ and $x_{2}$ refer to their displacements, and $k$ and $c$ are the stiffness and damping coefficients of the model, respectively. The gap $d$ represents the initial separation between the frames. In this analysis, the Kelvin-Voigt models are placed in each pounding story; Figure 2.b depicts an example of two 3 and 5-story colliding frames.

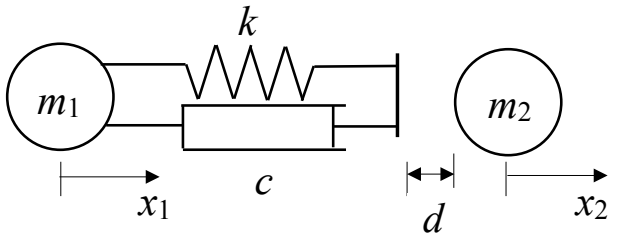

(a) Distribution of Kelvin-Voigt models

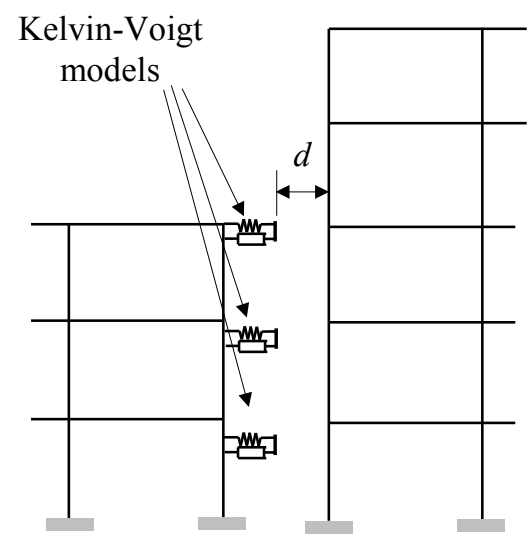

(b) Kelvin-Voigt model during impact

Figure 2: Lumped Kelvin-Voigt models for pounding simulation

The stiffness coefficient $k$ does not have a deep effect; as suggested in [Muthukumar, Des Roches 2006] it is selected to be higher than the axial stiffness of the longest colliding slab. Conversely, the damping coefficient $c$ has proven extremely high influence in the impact simulation. It is commonly selected after the coefficient of restitution $r$, being defined as the ratio between the post-impact and initial relative velocities between the colliding masses:

$$
r=\frac{v_{2}^{\prime}-v_{1}^{\prime}}{v_{1}-v_{2}}
$$

In equation (7), $v_{1}$ and $v_{2}$ are the initial velocities of the left and right slabs, respectively, and $v^{\prime}{ }_{1}$ and $v_{2}^{\prime}$ are the corresponding after-impact velocities. Equation (7) shows that $r$ ranges between 0 (plastic impact) and 1 (elastic impact). The physical meaning of the coefficient of restitution is more obvious than the one of the damping parameter; therefore, commonly it is preferred to start the process by selecting the value of $r$. In this study, two approaches are considered, the traditional formulation of [Anagnostopoulos 2004] and a more recent one [Kharazian 2017; López-Almansa, Kharazian 2018]. The traditional approach is based on neglecting, 
during impact, the influence of the structures of the colliding buildings and of the seismic excitation. The following inverse relations between $r$ and the damping ratio $\zeta$ of the Kelvin-Voigt model are obtained

$$
\zeta=-\ln r /\left(\pi^{2}+\ln ^{2} r\right)^{1 / 2} \quad r=e^{\frac{-\zeta \pi}{\left(1-\zeta^{2}\right)^{1 / 2}}}
$$

The expression linking $\zeta$ and $c$ is $\zeta=\frac{c}{2} \sqrt{\frac{m_{1}+m_{2}}{k m_{1} m_{2}}}$. This formulation has been used by many researches, showing repeatedly its efficiency. The works [Kharazian 2017; López-Almansa, Kharazian 2018] propose another approach that releases some of the assumptions in the traditional one; in that case, the relation between $r$ and $\zeta$ is given by a simple algorithm.

\subsection{Soil-Structure interaction}

Soil-Structure Interaction (SSI) is relevant to this study, mainly given its significant influence on the pounding effects [Kharazian, Lopez-Almansa 2017; Kharazian 2017]. Next paragraphs describe the considered models of interaction for spread footings and mat foundations, respectively. In both cases, SSI is represented by linear models, and two soil types are considered, namely B and C [EN-1998 2005].

SSI for isolated foundation is represented by an uncoupled spring model [FEMA 356 2000] consisting of elastic springs and dashpots linking the foundation (pad) footings and the underlying soil. In this context, "uncoupled" refers to the lack of relation between the stiffness and the damping of the springs and the dashpots that correspond to different degrees of freedom (directions). The foundation members are infinitely rigid compared to the soil. Given that this study is 2-D, each spring has horizontal, vertical and rotational (rocking) stiffness coefficients [Kharazian 2017].

In the mat foundation, SSI is represented by a coupled spring model [Harden 2003]; "coupled" refers to indirect consideration of rotational stiffness by increasing the corresponding parameter of the springs located at slab ends. The foundation slab stiffness is infinitely higher than the soil one (rigid mat). The equivalent width of the foundation slab that actually cooperates with the frame is determined according to [ACI-318-11 2011] as $1.5 \mathrm{~h}$ at both column sides, where $h$ is the slab depth. The horizontal and vertical stiffness coefficients are the same than for isolated foundation; the rotational (rocking) stiffness coefficient is given by another expression [Kharazian 2017].

\subsection{Modal analysis}

Linear modal analyses have been conducted. Two types of analyses are performed: in the first case, the bending stiffness of beams and columns refers to the moments of inertia of the gross section, and in the second case, such stiffness are reduced to account for the cracking effect [FEMA 356 2000]; the reducing factors are 0.7 and 0.5 for columns and beams, respectively. Table 2 displays the fundamental periods of each prototype building in three types of situations: by neglecting the SSI, and by considering SSI with isolated and mat foundation, 
respectively. When SSI is taken into consideration, $\mathrm{b}$ and $\mathrm{c}$ refer to stiff and soft soil type, respectively [EN-1998 2005].

\begin{tabular}{cccccc}
\hline \multirow{2}{*}{ Building } & \multicolumn{5}{c}{ SSI } \\
\cline { 2 - 6 } & NO & ISOL. (B) & ISOL. (C) & MAT (B) & MAT (C) \\
\hline 3-story 5-bay & $0.293 / 0.374$ & $0.295 / 0.376$ & $0.317 / 0.394$ & $0.295 / 0.376$ & $0.309 / 0.396$ \\
3-story 2-bay & $0.280 / 0.359$ & $0.282 / 0.360$ & $0.306 / 0.380$ & $0.281 / 0.361$ & $0.291 / 0.367$ \\
5-story 5-bay & $0.524 / 0.667$ & $0.526 / 0.669$ & $0.551 / 0.689$ & $0.526 / 0.669$ & $0.539 / 0.681$ \\
5-story 2-bay & $0.501 / 0.642$ & $0.504 / 0.644$ & $0.542 / 0.666$ & $0.503 / 0.644$ & $0.512 / 0.652$ \\
\hline
\end{tabular}

Table 2: Fundamental periods (s) of the representative buildings without / with cracking

The figures in Table 2 show that the simplified consideration of cracking generates a significant elongation of the fundamental period. Table 2 shows also that the consideration of the SSI slightly elongates the fundamental period of the buildings; as expected, the softer the soil, the higher the lengthening. Comparison between isolated and mat foundation reveals negligible or no influence.

\section{SEISMIC INPUTS CONSIDERED IN THE STUDY}

\subsection{Selection criteria}

This study is oriented to provide general remarks on buildings undergoing strong ground motions; therefore, the inputs should be selected to represent the actual conditions in any type of high seismicity regions. The inputs are selected based on two issues: (i) the forward-directivity (near-fault) effects, and (ii) the soil type. The near- fault effects are relevant, given the presence of velocity pulses; they are important, since the sudden delivery of input energy in a short time interval magnifies the input damaging potential [Zhai et al. 2013]. Regarding the soil type, it has a direct effect on the frequency content of the accelerogram.

\subsection{Selected inputs}

Given the considerations in the previous paragraph, four representative inputs are selected; are obtained combining the presence or absence of velocity pulses, and stiff and soft soil conditions. Table 3 depicts the most relevant characteristics of the four chosen inputs [PEER 2017]. $I_{\mathrm{A}}$ is the Arias Intensity [Arias 1970] given by $I_{\mathrm{A}}=\frac{\pi}{2 g} \int \ddot{x}_{\mathrm{g}}^{2} d t$ where $\ddot{x}_{\mathrm{g}}$ is the input ground acceleration (equation (1)); $I_{\mathrm{A}}$ is an estimator of the input severity. $P I$ and $E_{\mathrm{p}}$ quantify the relevance of the velocity pulses. $P I$ is the pulse index [Baker 2007], ranging between 0 and 1; records scoring above 0.85 and below 0.15 are classified as pulses and non-pulses, respectively. $E_{\mathrm{p}}$ is the relative pulse energy [Zhai et al. 2013], representing the portion of the total energy of the ground motion that corresponds to the pulse; the pulse is extracted by the peak-point method [Dickinson, Gavin 2010]. Values of $E_{\mathrm{p}}$ greater than 0.3 correspond to pulse-like records and values equal to or below 0.3 are ambiguous. The Trifunac duration is defined as the time between the $5 \%$ and the $95 \%$ of the Arias Intensity [Trifunac, Brady 1975]. The hypocentral distance corresponds to the straight separation between the hypocenter and the recording station. The closest distance corresponds to the shortest way to the rupture surface [PEER 2017]. $v_{\mathrm{s}, 30}$ is the weighted harmonic average shear wave velocity in the top $30 \mathrm{~m}$. The soil type corresponds to the classification of the Eurocode 8 [EN-1998 2005]. 


\begin{tabular}{|c|c|c|c|c|c|c|c|c|c|c|c|}
\hline $\begin{array}{c}\text { Earthquake / } \\
\text { Year / } M_{\mathrm{w}}\end{array}$ & $\begin{array}{l}\text { Hypo- } \\
\text { center } \\
\text { depth } \\
(\mathbf{k m})\end{array}$ & Station & Comp. & $\begin{array}{c}\text { PGA } \\
\text { (g) }\end{array}$ & $\begin{array}{c}I_{\mathrm{A}} \\
(\mathrm{m} / \mathrm{s})\end{array}$ & $P I$ & $E_{\mathrm{p}}$ & $\begin{array}{c}\text { Trifunac } \\
\text { duration } \\
\text { (s) }\end{array}$ & $\begin{array}{c}\text { Hypo- } \\
\text { central / } \\
\text { closest } \\
\text { distance } \\
(\mathbf{k m}) \\
\end{array}$ & $\begin{array}{c}\begin{array}{c}\text { Soil } \\
\text { type }\end{array} \\
(\mathrm{EC} 8) \\
/ v_{\mathrm{s}, 30} \\
(\mathrm{~m} / \mathbf{s}) \\
\end{array}$ & Name \\
\hline $\begin{array}{c}\text { Northridge / } \\
1994 \text { / } 6.7\end{array}$ & 17.5 & $\begin{array}{l}\text { Sylmar - Ol- } \\
\text { ive View }\end{array}$ & CDMG24514 & 0.84 & 5.01 & 1.0 & 0.61 & 5.32 & $\begin{array}{c}24.24 / \\
5.3\end{array}$ & $\begin{array}{c}\mathrm{B} / \\
440.5\end{array}$ & P B \\
\hline $\begin{array}{c}\text { Northridge / } \\
1994 \text { / } 6.7\end{array}$ & 17.5 & $\begin{array}{c}\text { Newhall - W } \\
\text { Pico }\end{array}$ & UCS90056 & 0.42 & 1.54 & 1.0 & 0.78 & 6.25 & $\begin{array}{c}27.76 / \\
5.48\end{array}$ & $\begin{array}{c}\mathrm{C} / \\
285.9\end{array}$ & $\mathrm{PC}$ \\
\hline $\begin{array}{l}\text { Victoria / } \\
1996 / 6.3\end{array}$ & 11 & Cerro Prieto & UCSD6604 & 0.64 & 1.99 & 0.0062 & 0.17 & 8.25 & $\begin{array}{l}35.48 / \\
14.37\end{array}$ & $\begin{array}{c}\text { B / } \\
471.5\end{array}$ & NP B \\
\hline $\begin{array}{c}\text { Northridge / } \\
1994 \text { / } 6.7\end{array}$ & 17.5 & Saticoy St & USC90003 & 0.46 & 4.63 & 0.0104 & 0.21 & 10.62 & $\begin{array}{c}17.83 / \\
12.09 \\
\end{array}$ & $\begin{array}{c}\mathrm{C} / \\
280.9 \\
\end{array}$ & NP C \\
\hline
\end{tabular}

Table 3: Selected input records

Table 3 shows that the first two inputs are pulse-like, and that the last two ones are not. Next in this paper, the four inputs in Table 3 are termed P B, P C, NP B and NP C, respectively; in this notation, "P" and "NP" account for Pulse and Non-Pulse, respectively, and "B" and "C" refer to soil type.

To highlight the major characteristics of the four selected ground motion records, Figure 3 displays their time histories.

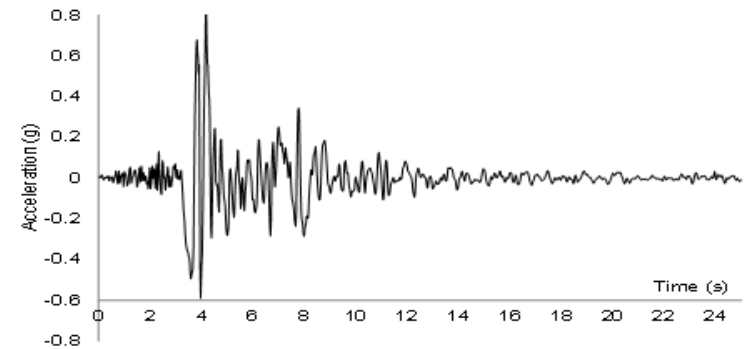

(a) Northridge Sylmar-Olive (P B)

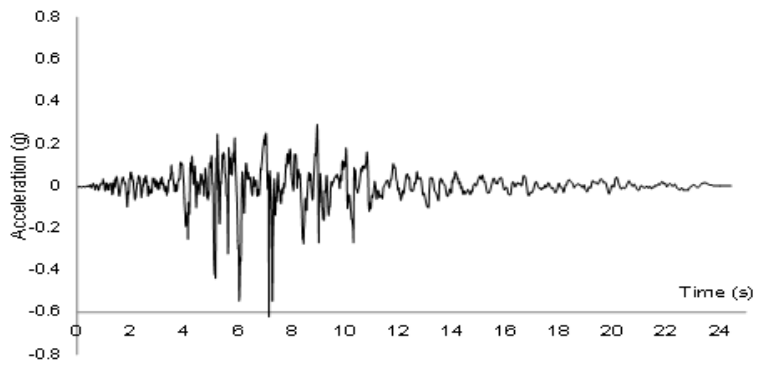

(c) Victoria Cerro Prieto (NP B)

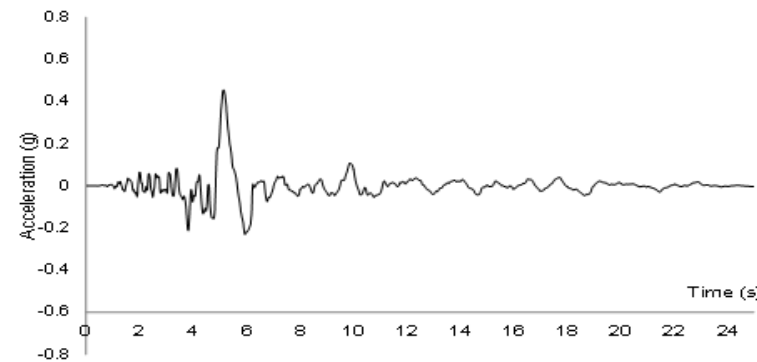

(b) Northridge W Pico Canyon (P C)

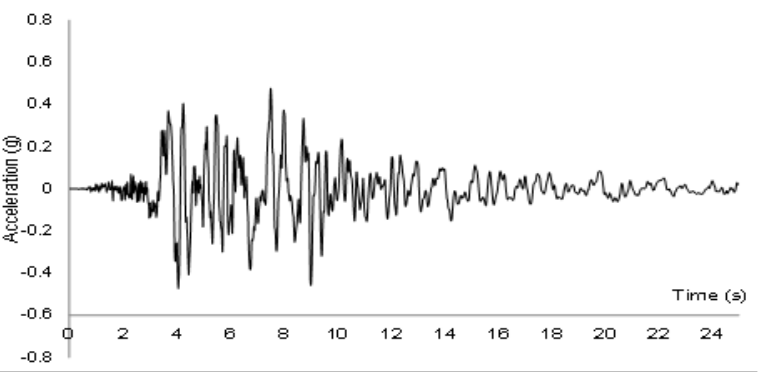

(d) Northridge Saticoy St (NP C)

Figure 3: Considered input accelerograms

The accelerograms displayed in Figure 3 confirm that those in the top plots are pulse-like, while those in the bottom plots are not. As well, the left plots exhibit greater high-frequency contents than those in the right plots, this being coherent with the soil type. Deeper discussions can be found in [Kharazian 2017].

\subsection{Response spectra of the selected inputs}

To point out the period-dependent characteristics of the selected accelerograms, their absolute acceleration and input energy response spectra are displayed in Figure 4 and Figure 5, 
respectively. The acceleration spectra are determined using the software SeismoSignal [SeismoSoft 2017]. The input energy spectra are computed after equation (3); then, such energy is expressed in terms of equivalent velocity according to equation (6). In equation (3), the structural behavior is assumed to be linear; noticeably, according to the Housner-Akiyama theory [Akiyama 1985], the obtained results are also somehow valid for nonlinear behavior, given that the input energy is roughly independent on the constitutive law. The plots in Figure 5 correspond to damping $5 \%$.

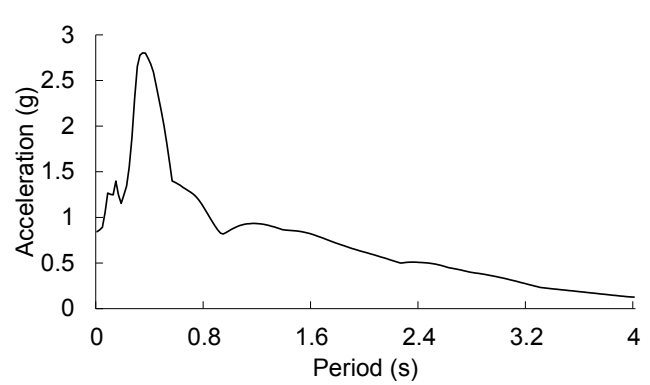

(a) Northridge Sylmar-Olive (P B)

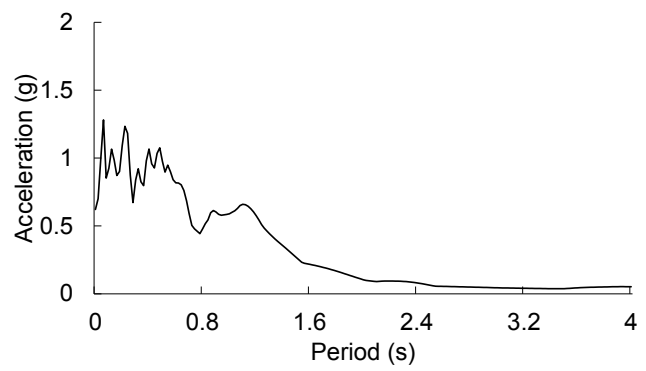

(c) Victoria Cerro Prieto (NP B)

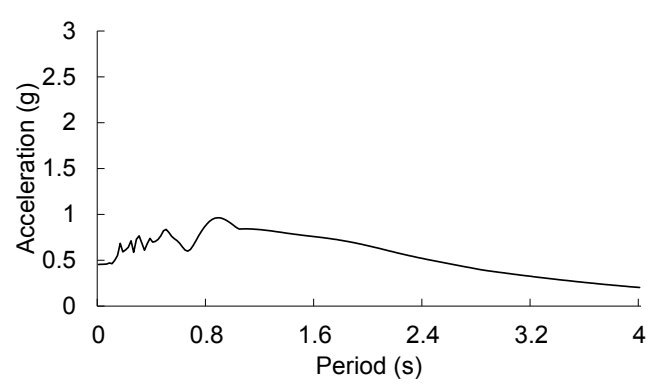

(b) Northridge W Pico Canyon (P C)

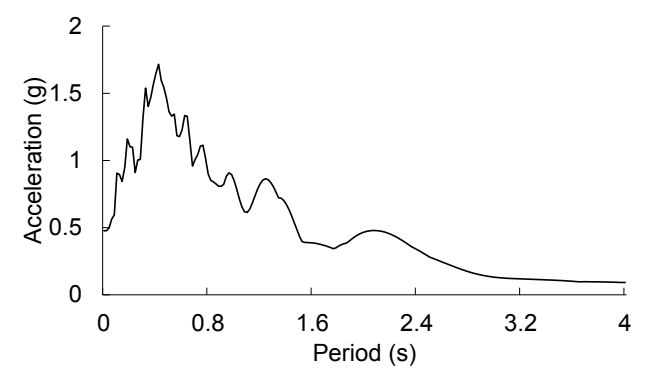

(d) Northridge Saticoy St (NP C)

Figure 4: Absolute acceleration response spectra of the considered inputs

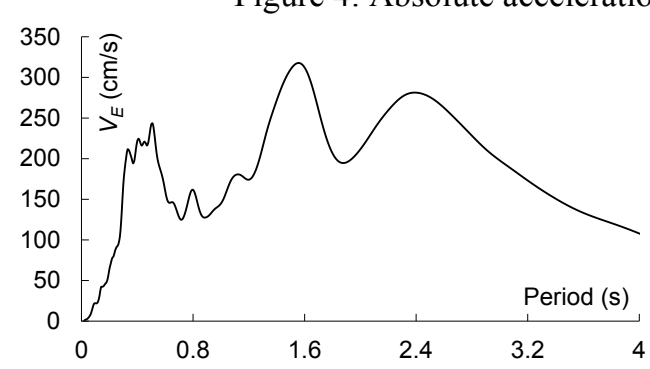

(a) Northridge Sylmar-Olive (P B)

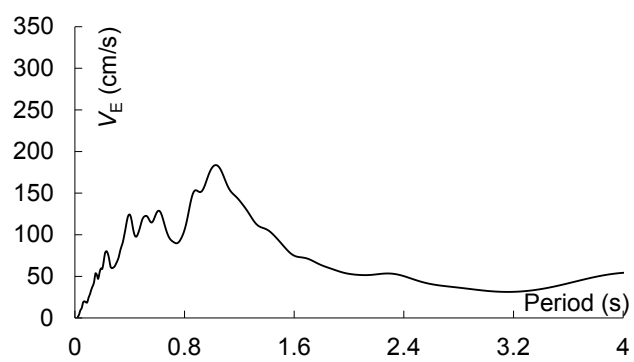

(c) Victoria Cerro Prieto (NP B)

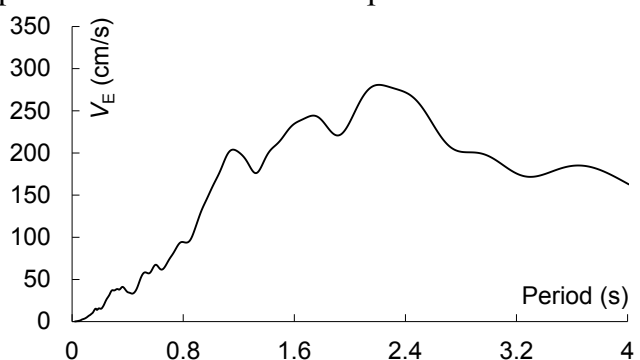

(b) Northridge W Pico Canyon (P C)

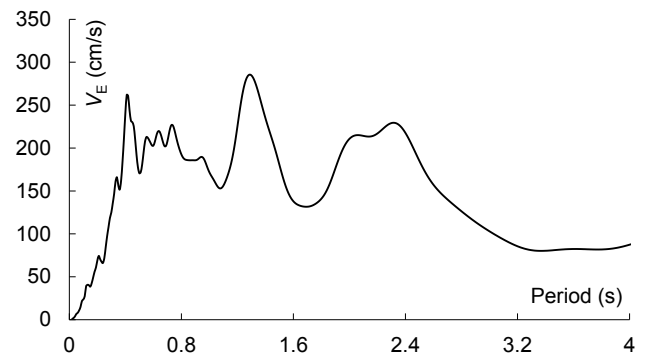

(d) Northridge Saticoy St (NP C)

Figure 5: Input energy response spectra of the considered inputs 
The spectra in Figure 4 confirm the considerations stated after the accelerograms in Figure 3. Comparison among the spectra in Figure 4 and Figure 5 show that the spectra corresponding to the same input exhibit peaks for the same periods, although those of energy spectra are higher for longer periods; this similarity among peaks is coherent with the broad likeness among energy and velocity spectra [Akiyama 1985].

As discussed in section 2, the $V_{\mathrm{D}}$ spectrum is commonly obtained by multiplying the $V_{\mathrm{E}}$ spectrum by a convenient value of the $V_{\mathrm{D}} / V_{\mathrm{E}}$ ratio; such ratio depends mainly on the damping factor $\zeta$, the displacement ductility $\mu$ (i.e. the ratio between the maximum and yield displacements), and the building fundamental period $T_{\mathrm{F}}$. References [Yazgan 2012; López-Almansa et al. 2013] contain linear regression studies providing average expressions $V_{\mathrm{D}} / V_{\mathrm{E}}=b-a T_{\mathrm{F}}$ where coefficients $a$ and $b$ depend on $\zeta$ and $\mu$. In this study, it is assumed that $\zeta=0.05$; then, the available values of $a$ and $b$ in terms of $\mu$ are listed next. For $\mu=2, a=0.042, b=0.67$, for $\mu=3, a=0.045, b=0.77$, for $\mu=5, a=0.049, b=0.84$, for $\mu=10, a=0.054, b=0.88$, for $\mu$ $=15, a=0.055, b=0.88$, for $\mu=20, a=0.052, b=0.87$. For $\mu=1$, obviously $V_{\mathrm{D}} / V_{\mathrm{E}}=0$, i.e. $a=0, b=0$. For values of $\mu \geq 2$, linear interpolation provide enough accuracy. Conversely, for values of $\mu$ between 1 and 2 , linear interpolation would deliver too small $V_{\mathrm{D}} / V_{\mathrm{E}}$ ratios; alternative interpolation criteria [Yazgan 2012, López-Almansa et al. 2013] are suggested instead. Table 4 displays values of the $V_{\mathrm{D}} / V_{\mathrm{E}}$ ratio for the four selected inputs (Table 3 ) and the four chosen buildings (Table 1). In Table 4, the yield displacements are obtained after the capacity curves) derived from pushover analyses. Obviously, if $\mu<1$, the hysteretic energy is zero and no values of $a$ and $b$ are provided. Noticeably, in Table 4 only soil $\mathrm{C}$ is considered in the cases with SSI, given that for stiff soil (B) the effect of SSI is less relevant and no dynamic analyses have been performed (Section 6).

\begin{tabular}{|c|c|c|c|c|c|c|c|c|c|c|c|c|c|}
\hline \multirow{2}{*}{ Building } & \multirow{2}{*}{$\begin{array}{l}\text { In- } \\
\text { put }\end{array}$} & \multicolumn{4}{|c|}{ NO SSI } & \multicolumn{4}{|c|}{$\begin{array}{l}\text { SSI FOR ISOLATED } \\
\text { FOUNDATION }\end{array}$} & \multicolumn{4}{|c|}{ SSI FOR MAT FOUNDATION } \\
\hline & & $\mu$ & $a$ & $b$ & $\begin{array}{l}V_{\mathbf{D}} / \\
V_{\mathbf{E}}\end{array}$ & $\mu$ & $a$ & $b$ & $V_{\mathrm{D}} / \boldsymbol{V}_{\mathrm{E}}$ & $\mu$ & $a$ & $b$ & $\begin{array}{c}V_{\mathbf{D}} / \\
\boldsymbol{V}_{\mathbf{E}}\end{array}$ \\
\hline \multirow{4}{*}{$\begin{array}{l}\text { 3-story } 5- \\
\text { bay }\end{array}$} & P B & 1.612 & 0.041 & 0.631 & 0.618 & - & - & - & - & - & - & - & - \\
\hline & $\mathrm{PC}$ & 0.327 & - & - & 0 & 0.427 & - & - & 0 & 0.508 & - & - & 0 \\
\hline & NP B & 0.529 & - & - & 0 & - & - & - & - & - & - & - & - \\
\hline & NP C & 0.554 & - & - & 0 & 0.748 & - & - & 0 & 0.855 & - & - & 0 \\
\hline \multirow{4}{*}{$\begin{array}{l}\text { 3-story 2- } \\
\text { bay }\end{array}$} & P B & 1.037 & 0.039 & 0.574 & 0.562 & - & - & - & - & - & - & - & - \\
\hline & $\mathrm{PC}$ & 0.311 & - & - & 0 & 0.312 & - & - & 0 & 0.256 & - & - & 0 \\
\hline & NP B & 0.394 & - & - & 0 & - & - & - & - & - & - & - & - \\
\hline & NP C & 0.436 & - & - & 0 & 0.496 & - & - & 0 & 0.465 & - & - & 0 \\
\hline \multirow{4}{*}{$\begin{array}{l}\text { 5-story 5- } \\
\text { bay }\end{array}$} & P B & 1.836 & 0.042 & 0.654 & 0.634 & - & - & - & - & - & - & - & - \\
\hline & $\mathrm{PC}$ & 0.751 & - & - & 0 & 0.812 & - & - & 0 & 0.829 & - & - & 0 \\
\hline & NP B & 1.193 & 0.040 & 0.589 & 0.566 & - & - & - & - & - & - & - & - \\
\hline & NP C & 1.273 & 0.040 & 0.597 & 0.574 & 1.266 & 0.040 & 0.597 & 0.572 & 1.302 & 0.040 & 0.600 & 0.576 \\
\hline \multirow{4}{*}{$\begin{array}{l}\text { 5-story 2- } \\
\text { bay }\end{array}$} & P B & 1.733 & 0.041 & 0.643 & 0.615 & - & - & - & - & - & - & - & - \\
\hline & $\mathrm{PC}$ & 0.631 & - & - & 0 & 0.728 & - & - & 0 & 0.689 & - & - & 0 \\
\hline & NP B & 0.903 & - & - & 0 & - & - & - & - & - & - & - & - \\
\hline & NP C & 1.287 & 0.040 & 0.599 & 0.576 & 1.110 & 0.039 & 0.581 & 0.563 & 1.263 & 0.040 & 0.596 & 0.573 \\
\hline
\end{tabular}

Table 4: $V_{\mathrm{D}} / V_{\mathrm{E}}$ ratio in terms of displacement ductility and period for the considered buildings

The $V_{\mathrm{D}} / V_{\mathrm{E}}$ ratio is little influenced by the approximate consideration of cracking in the determination of the building fundamental period; this is expected, given the little influence of the period in the $V_{\mathrm{D}} / V_{\mathrm{E}}$ ratio. Thus Table 4 show the average between the ratios for the cracked and uncracked periods. 


\section{DYNAMIC ANALYSIS OF THE LONE AND COLIDING PROTOTYPE BULDINGS}

This section describes the nonlinear dynamic response of the prototype buildings in section 3 to the accelerograms in section 5; the analyses employ the models in section 4 . Two types of analyses are conducted: single (lone) buildings and pairs of colliding buildings. In this last case, four pairs are contemplated: 3 -story 5-bay vs. 5-story 2-bay, 5-story 5-bay vs. 5-story 2-bay, 5story 5-bay vs. 3-story 2-bay and 5-story 2-bay vs. 3-story 2-bay; noticeably, the pounding among two alike buildings is not analyzed, because collision is not feasible to occur. Four each building or pair of buildings, three situations regarding soil-structure interaction are analyzed: neglecting such interaction (no SSI), and interaction for isolated (ISOL.) and mat foundation (MAT). In the cases with SSI (ISOL. and MAT), only the inputs for soft soil (P C and NP C, see Table 3) are considered, given that, for stiff soil (P B and NP B), the effect of SSI is rather negligible [Kharazian 2017]. Briefly, 32 and 32 analyses are performed for the lone buildings and the pairs of buildings, respectively.

The time integration is carried out using the Newmark algorithm with $\gamma=0.5$ and $\beta=0.25$ (constant acceleration interpolation). Inside each time step, the maximum number of iterations is 300 and the convergence is verified based on displacement and rotation; the displacement and rotation tolerances are $10^{-4} \mathrm{~m}$ and $10^{-5} \mathrm{rad}$, respectively. The damping matrix is generated, with a classical Rayleigh model, as proportional to the tangent stiffness [Petrini et al. 2008]; the assumed damping ratio is $5 \%$.

In any nonlinear analysis, time step selection is a key issue, since the usual criteria for linear analysis do not apply, and instabilities might arise; noticeably, this might happen even in the supposedly unconditionally stable Newmark algorithm. In pounding analysis, this subject is still more crucial, since pounding generates sudden changes in extremely short time intervals, thus leading to important accelerations and involving higher-mode response. In this research, the time increment is selected starting with a coarse time discretization $(\Delta t=0.01 \mathrm{~s})$ and then refining it progressively until obtaining similar results regardless of the considered sampling period. Satisfactory performance has been achieved with $\Delta t=0.0005 \mathrm{~s}$ [Kharazian 2017].

\section{RESULTS FOR ENERGY}

This section presents and discusses the results of input $\left(E_{\mathrm{I}}\right)$ and hysteretic $\left(E_{\mathrm{H}}\right)$ energy that constitute the main output of this paper. Two approaches are employed: (i) $E_{\mathrm{I}}$ and $E_{\mathrm{H}}$ are obtained from the dynamic analyses described in section 6, and (ii) $E_{\mathrm{I}}$ is determined from the energy spectra in Figure 5, and then $E_{\mathrm{H}}$ is obtained according to the formulation described in the paragraph before Table 4 (Section 5).

In the first approach, the input energy is determined after equation (3). However, in this work that equation cannot be applied directly, because it corresponds to a SDOF system; given that the dynamic behavior of the multi-story analyzed buildings can be broadly described with MDOF lumped masses models, the input energy for the whole building can be obtained as the sum of the contribution of each story:

$$
E_{\mathrm{I}}=-\int_{0}^{\mathrm{t}} \dot{\boldsymbol{x}}^{\mathrm{T}} \mathbf{M} \mathbf{r} \ddot{x}_{\mathrm{g}} d t=-\int_{0}^{t} \sum_{\mathrm{i}=1}^{\mathrm{N}} \dot{x}_{\mathrm{i}} m_{\mathrm{i}} \ddot{x}_{\mathrm{g}} d t=-\sum_{\mathrm{i}=1}^{\mathrm{N}} \int_{0}^{t} \dot{x}_{\mathrm{i}} m_{\mathrm{i}} \ddot{x}_{\mathrm{g}} d t
$$

In this expression, $\dot{x}_{\mathrm{i}}$ and $m_{\mathrm{i}}$ are the relative velocity and the mass of each story, respectively, $\ddot{x}_{\mathrm{g}}$ is the input (driving) ground acceleration (equation (1)), and $N$ is the number of floors of the building under consideration; the relative velocity $\dot{x}_{\mathrm{i}}$ is obtained after the conducted nonlinear analyses (section 6). Analogously, the hysteretic energy is calculated as the sum of the energy 
that is dissipated at each story (i.e. area encompassed by the shear force-drift displacement hysteresis loops):

$$
E_{\mathrm{H}}=\int_{0}^{t} \sum_{\mathrm{i}=1}^{\mathrm{N}} V_{\mathrm{i}} d \delta_{\mathrm{i}}=\sum_{\mathrm{i}=1}^{\mathrm{N}} \int_{0}^{t} V_{\mathrm{i}} d \delta_{\mathrm{i}}
$$

In this expression, $V_{\mathrm{i}}$ and $\delta_{\mathrm{i}}$ are the story shear force and the drift displacement, respectively. The first approach (equations (9) and (10)) is allegedly more accurate, since the second one involves several relevant simplifications: (i) representation of the buildings as SDOF systems, (ii) lack of consideration of the building fundamental period elongation due to its nonlinear behavior, (iii) representation of the building nonlinear behavior with an elastic-perfectly plastic model, and (iv) approximate determination of the $V_{\mathrm{D}} / V_{\mathrm{E}}$ ratios (Table 4).

One of the main issues in energy-based design of multistory buildings is the distribution among stories of the total hysteretic energy. Regarding this question, Figure 6 displays a comparison between the input and hysteretic energy for each story for a pair of colliding and lone buildings, respectively. These energies have been obtained with the $1^{\text {st }}$ approach (integration).

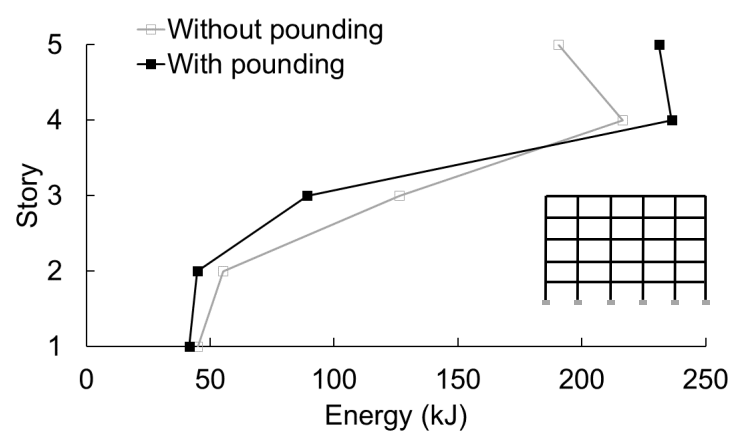

(a) Hysteretic energy. 5-story 5-bay frame (left)

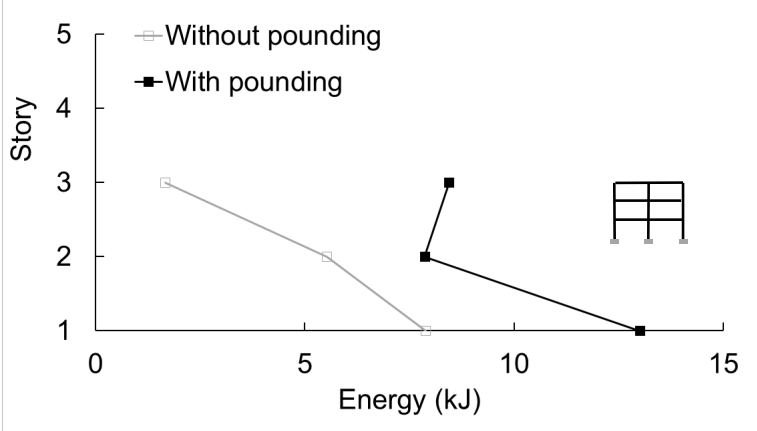

(b) Hyst. energy. 3-story 2-bay frame (right)

Figure 6: Responses w w/o pounding. 5-story 5-bay | 3-story 2-bay. No SSI. Northridge Saticoy St. (NP C)

According to this figure, the distribution of hysteretic energy among stories is scarcely affected by pounding. This conclusion should be taken as tentative, given the limited number of buildings and ground motions considered in this study.

\section{CONCLUSIONS}

This paper discusses the influence of SSI (Soil-Structure Interaction) and pounding between adjoining buildings in their input and hysteretic energies; this study is conducted on two pairs of low-rise (3 and 5-story) RC colliding buildings. Such energies are determined by direct integration of the dynamic response (accurate formulation) and after individual energy spectra of the seismic inputs (simplified formulation); the agreement between both strategies is only reasonable. Preliminary results indicate that the input energy shows high scattering, probably due to difficulty in estimating the equivalent nonlinear fundamental period. The distribution among stories of the total input and hysteretic energy is being investigated.

\section{ACKNOWLEDGEMENTS}

This work has received financial support from Spanish Government under projects BIA2017-88814-R and CGL2015-6591 (Feder funds). 


\section{REFERENCES}

[1] ACI-318-11. (2011). Building Code Requirements for Structural Concrete and Commentary (318R-11). American Concrete Institute.

[2] Akiyama H. (1985). Earthquake-resistant limit-state design for buildings. University of Tokyo Press, Tokyo.

[3] Anagnostopoulos SA. (1988). Pounding of buildings in series during earthquakes. Earthquake Engineering and Structural Dynamics, 16(3):443-456.

[4] Anagnostopoulos SA. (2004). Equivalent viscous damping for modeling inelastic impacts in earthquake pounding problems. Earthquake Engineering and Structural Dynamics, 33(8):897-902.

[5] Benavent-Climent A, López-Almansa F, Bravo DA. (2010). Design energy input spectra for moderate-to-high seismicity regions based on Colombian earthquakes. Soil Dynamics \& Earthquake Engineering. 30(11):11291148 .

[6] Benavent-Climent A, Pujades LG, López-Almansa F. (2002). Design energy input spectra for moderate-seismicity regions. Earthquake Engineering and Structural Dynamics, 31:1151-1172.

[7] Decanini LD, Mollaioli F. (2001). An energy-based methodology for the seismic assessment of seismic demand. Soil Dynamics and Earthquake Engineering 21:113-137.

[8] Fajfar P, Vidic T. (1994). Consistent inelastic design spectra: hysteretic and input energy. Earthquake Engineering and Structural Dynamics 23:523-537.

[9] FEMA 356. (2000). Prestandard and Commentary for the Seismic Rehabilitation of Buildings. Federal Emergency Management Agency.

[10] Harden CW. (2003). Numerical modelling of the nonlinear cyclic response of shallow foundations, University of California, Irvine.

[11] Housner GW. (1956). Limit design of structures to resist earthquakes. First World Conference on Earthquake Engineering 5:1-12.

[12] Kharazian A, Lopez-Almansa F. (2017). State-of-the-art of research on seismic pounding between buildings with aligned slabs. Archives of Computational Methods in Engineering. https://doi.org/10.1007/s11831-0179242-3.

[13] Kharazian A. (2017). Analysis of seismic pounding of moderate height RC buildings with aligned slabs. Doctoral Dissertation, Technical University of Catalonia.

[14] Kharazian A, López Almansa F, Benavent Climent A, Gallego A. (2018). Shaking table testing on seismic pounding of a RC building structure. $1^{\text {st }}$ Conference on Structural Dynamics (DinEst 2018). Madrid.

[15] Kuwamura H, Galambos TV. (1989). Earthquake load for structural reliability. Journal of Structural Engineering ASCE 115(6):1446-1462.

[16] Kuwamura H, Kirino Y, Akiyama H. (1994). Prediction of earthquake energy input from smoothed Fourier amplitude spectrum. Earthquake Engineering and Structural Dynamics 23:1125-1137.

[17] Lawson RS, Krawinkler H. (1995). Cumulative damage potential of seismic ground motion. $10^{\text {th }}$ European Conference on Earthquake Engineering 1079-1086.

[18] López-Almansa F, Yazgan AU, Benavent-Climent A. (2013). Design energy input spectra for high seismicity regions based on Turkish registers. Bulletin of Earthquake Engineering 11:885-912.

[19]López-Almansa F, Kharazian A. (2018). New formulation for estimating the damping parameter of the Kelvin-Voigt model for seismic pounding simulation. Engineering Structures 175:284-295.

[20] Manfredi G. (2001). Evaluation of seismic energy demand. Earthquake Engineering and Structural Dynamics, 30:485-499.

[21] Muthukumar S, DesRoches R. (2006). A Hertz contact model with non-linear damping for pounding simulation. Earthquake Engineering and Structural Dynamics, 35(7):811-828.

[22] Petrini L, Maggi C, Priestley MJN, Calvi GM. (2008). Experimental verification of viscous damping modeling for inelastic time history analyses. Journal of Earthquake Engineering, 12(S1):125-145.

[23] SeismoSoft. (2017). A computer program for process strong-motion data. Available from URL www.Seismosoft.com.

[24] Teran-Gilmore A. (1996). Performance-based earthquake-resistant design of framed buildings using energy concepts. PhD Thesis, Department of Civil Engineering, University of California at Berkeley.

[25] Yazgan AU. (2012). Proposal of energy spectra for earthquake resistant design based on Turkish registers. Doctoral Dissertation. Technical University of Catalonia.

[26]Zhai C, Chang Z, Li S, Chen Z, Xie L. (2013). Quantitative Identification of Near-Fault Pulse-Like Ground Motions Based on Energy. Bulletin of the Seismological Society of America, 103(5):2591-2603. 